\title{
The Dose-Response Relationship between The triglyceride-glucose index and Risk of Diabetes Mellitus Using Publicly Available Data: A Longitudinal Study in Chinese Obesity adult population
}

jiacheng he ( $\square$ garxin@tom.com )

People's Hospital of Nanhai District

Original investigation

Keywords: triglyceride-glucose index, Diabetes Mellitus, Dose-Response

Posted Date: August 12th, 2021

DOl: https://doi.org/10.21203/rs.3.rs-786426/v1

License: (c) (i) This work is licensed under a Creative Commons Attribution 4.0 International License. Read Full License 


\section{Abstract}

\section{Background}

Triglyceride-glucose index (TyG index) is associated with type 2 diabetes mellitus (T2DM), but research on this relationship is limited in Obesity population. The purpose of this study was to evaluate the correlation between TyG index and the risk of incident T2DM in Chinese Obesity adult population.

Methods

80,919 participants with $\mathrm{BMI} \geq 24$ were selected from a prospective cohort study data which was collected between 2010 and 2016 across 32 sites and 11 cities in China.The risk of incident T2DM according to TyG index was estimated using multivariable Cox proportional hazards models and a twopiece wise linear regression model was developed to find out the threshold effect.The formula for TyG index was expressed as $\ln [$ fasting triglyceride leve $(\mathrm{mg} / \mathrm{dL}) \times$ fasting plasma glucose level $(\mathrm{mg} / \mathrm{dL}) / 2$ ].

Results

After follow-up, 3008 ( $3.7 \%$ ) patients developed T2DM. After adjusting for potential confounders, as a continuous variable, TyG index was associated with an increased risk of incident T2DM (adjusted hazard ratio (aHR), 3.81; 95\% confidence interval (95\% Cl), 3.56-4.09. Further analysis revealed a positive curvilinear association between TyG index and incident T2DM, with a saturation effect predicted at 9.328. When the TyG index was less than 9.328, the risk of incident T2DM increased significantly[HR 4.778 (4.149,5.462), $P<0.001]$, while the risk became gentle when beyond 9.328[HR 2.61 (2.123,3.209), $P<$ 0.001]. Subgroup analyses showed that the association between TyG index and incident T2DM stably existed in different subgroups.

Conclusions

TyG index was a significant predictor of subsequent risk of incident T2DM in Chinese Obesity adult population. An increase in TyG index of one unit increased the risk of developing T2DM by 3.81-fold.

\section{Introduction}

diabetes is a growing health problem imposing heavy financial burden on individuals and society [14].Almost one in four of patients with diabetes all over the world lives in China, which makes China become the country with the largest DM population in the world[5]. According to reports, the prevalence of diabetes in adults is $10.4 \%$ in China in 2013[6]. Therefore, early prevention and appropriate intervention to avoid diabetesls very necessary. The detection of early predictive markers for incident DM in adults is considered as a key point from a public health perspective.

Prospective studies have indicated insulin resistance (IR) is the main pathogenesis of diabetes, which is present many years before diagnosis[7-9]. Obviously, IR can improve the prediction of progression to 
diabetes. The hyperinsulinemic-euglycemic clamp (HIEC) techniquehas always been the gold standard for quantitative IR[10], but it is costly and timeconsuming to apply in clinical practice.The triglyceride glucose (TyG) index, which was proposed by Simental-Mendía et al. calculated by the formula, In[fasting triglycerides $(\mathrm{mg} / \mathrm{dL})$ fasting blood glucose $(\mathrm{mg} / \mathrm{dL}) / 2$ ], is a new marker that could measure insulin resistance in patients with diabetes. Using HIEC or in-vivo steady-state model assessment-IR (HOMA-IR) as a reference standard, some studies have confirmed the accuracy of its diagnosis of IR[11, 14-16]. Additionally, the TyG index could be obtained by calculations instead of a blood test, and it is inexpensively. Previous studies have shown that the TyG index was relevant with high risk of diabetes[1720]. In Asian populations, TYG index association with incident DM had been conducted in low-weight and normal-weight groups[21, 22]. But the relationship between TyG index and T2DM has not yet been studied in Chinese Obesity adult population.

Here, study data were downloaded freely and a secondary analysis was performed[23]. Our research goal was to evaluate the correlation of TyG index with the risk of developing incident DM in Chinese Obesity adult population.

\section{Methods}

\section{Data source}

Data was downloaded from the DATADRYAD website (www.datadryad.org. The DATADRYAD database allows others to freely obtain original data. In accordance with the Dryad Terms of Service, we gained the following Dryad data package: Chen, Ying et al. (2018), data from:Association of body mass index and age with incident diabetes in Chinese adults: a population-based cohort study, Dataset, https://doi.org/10.5061/dryad.ft8750v.The following variables were included in the database materials:sex, age, BMI, drinking, smoking, family history of diabetes, low density lipoprotein cholesterol (LDL-C), high density lipoprotein cholesterol (HDL-C), total cholesterol (TC), TG, FPG, concentration of creatinine (CCR), aspartate aminotransferase (AST), alanine aminotransferase (ALT), systolic blood pressure (SBP), diastolic blood pressure (DBP), FPG of final visit, incident diabetes at follow up and follow-up time.In the original paper[23], the authors declared that they have relinquished copyright and relevant ownership of the database. Thus, this database can be used for secondary analyses without violating the authors' rights.

\section{Study population}

Data were obtained from a database provided by the Rich Healthcare Group in China, and the study enrolled 685,277 participants who received a health check and were at least 20 years old with at least two visits between 2010 and 2016 across 32 sites and 11 cities in China (Shanghai, Beijing, Nanjing, Suzhou, Shenzhen, Changzhou, Chengdu, Guangzhou, Hefei, Wuhan, Nantong). The data we got has been initially screened, as follows: (1) no available information about weight, height, gender, fasting plasma glucose value at baseline, (2) extreme BMI values ( $<15 \mathrm{~kg} / \mathrm{m} 2$ or $>55 \mathrm{~kg} / \mathrm{m} 2$ ), (3) excluded participants with visit intervals less than 2 years, (4) participants diagnosed with diabetes at baseline and participants with 
undefined diabetes status at follow-up[23]. Finally, 211,833 participants took part in the analysis. The institutional ethics committee did not require any obtainment of study approval or informed consent for the retrospective component of the research. For further research, some data were removed from the analysis cohort:excluded BMl<24 at baseline(128893); missing TyG values at baseline(2021). In total, 80,919 subjects $(58,470$ males and 22,449 females) were included for analysis in this study(Figure 1 ).

\section{Measurement of the TyG index and other covariates}

Researchers obtained information (values) for our retrospective cohort study. The design of the study has been documented elsewhere[23]. Demographic characteristics, lifestyle, disease history, and medical history were obtained by a detailed questionnaire. Height measurement was accurate to $0.1 \mathrm{~cm}$. Weight measurement was accurate to $0.1 \mathrm{~kg}$, required to wear lightweight and no shoes. BMI was calculated as weight / height squared $(\mathrm{kg} / \mathrm{m} 2)$. Fasting venous blood was drawn to detect serum LDL, TG, TC, HDL-C, FPG, BUN, Ccr, ALT and AST values by an automatic biochemical analyzer (Beckman 5800). The TyG index was calculated as $\mathrm{Ln}[\mathrm{FPG}(\mathrm{mg} / \mathrm{dL}) \times$ fasting $T G(\mathrm{mg} / \mathrm{dL}) / 2][23]$. Because this was a retrospective cohort study, observation bias was naturally reduced.

\section{Ascertainment of diabetes}

Diabetes was defined according to FPG $\geq 126 \mathrm{mg} / \mathrm{dL}$ or self-reported diabetes. Ascertainment of diabetes depended on the date of diagnosis or the last visit.

\section{Statistical Analysis}

Continuous variables (normal distribution) are presented as mean with standard deviation (SD) and continuous variables (skewed distribution) are expressed as median with interquartile range (IQR).Categorical variables are presented as frequencies and percentages. The remaining missing values were imputed by multivariable chained imputation with fully conditional specification[24]; imputed and reported results were similar.We used the chi-square test, one-way analysis of variance, or Kruskal-Wallis test to examine the statistical differences in the groups stratified by TyG index quartiles.We employed the univariate and multivariate Cox proportional hazard models to assess the relationship between TyG index and the risk of DM.We used three models: model 1, a crude (univariate) model; model 2, adjusted for age and sex; and model 3, adjusted for age, sex, height, weight, LDL, TC, HDL-C, BUN, Ccr, AST, ALT, SBP, DBP, drinking status, smoking status and family history of diabetes. In the models, we used a median value in each quartile of TyG index to perform the linear trend tests. In addition, the nonlinear relationship between TyG and incident DM was estimated using the Cox proportional hazards regression model with cubic spline functions. To find modifications and interactions, we used a stratified linear regression model and likelihood ratio test in the different subgroups according to sex, age ( $<65$ years or $\geq 65$ years), smoking status (never, ever, or current), drinking status (never, ever, or current), family.histroy.of.diabetes, HBP, and BUN( $<=7.1$ or $>7.1$ ). We used the Statistical Packages R (The R Foundation, Vienna, Austria) to analyze the data. When the calculated $P$ value was less than 0.05 , the statistical difference was considered significant. 


\section{Results}

\section{Baseline characteristics of patients}

Baseline characteristics of study participants according to quartiles of triglyceride-glucose index were presented in Table 1.A total of 80,919 subjects $(72.3 \%$ male and $27.7 \%$ female) were involved in this study. the baseline characteristics of the participants grouped by quartile of TyG index.the mean age of the participants was $45.1 \pm 13.0$ years.After an average follow-up of $3.1 \pm 0.9$ years, 3008 ( $3.7 \%$ ) participants were developed diabetes mellitus.Participants in the highest group of TyG (Q4) had higher values of age, height,weight, TC, TG, FPG, BUN, Ccr, ALT, AST, SBP, and DBP. And consisted of more males, smokers, drinkers, hypertension and family history of diabetes than the other groups(Q1-3).Participants with the highest TyG (Q4) had lower values in HDL than those with lower TyG (Q1-Q3).

\section{Univariate analysis for diabetes mellitus}

Table 2 presents the results of the univariate analysis for the association between risk factors and incident DM. Using the univariate Cox proportional hazard model, we discovered that SCR was not associated with DM. In contrast, univariate analysis showed that age, BMI, LDL, TC, TG, FPG, TyG index, ALT, AST, Ccr, SBP, DBP, drinking and family history of diabetes were positively related to future risk of diabetes. Moreover, never smoking and height were negative correlation. Furthermore, compared with males, females showed a lower risk of diabetes.ever smoke status was not associated with DM compared with Current smoke status.

\section{Unadjusted and Adjusted Cox Proportional Hazard Model}

We used Cox proportional hazard models to assess the independent effects of TyG index on the risk of incident DM (univariate and multivariate Cox proportional hazard models). Table 3 presents the effect sizes (hazard ratio (HR) and 95\% confidence intervals $(95 \% \mathrm{Cl})$ ). In the unadjusted model (model 1), an increase in TyG index of one unit was associated with a 2.83-fold higher risk of incident T2DM (HR2.83 , 95\% $\mathrm{Cl}$ 2.69-2.99). In model 2, an increase in TyG index of one unit increased the risk of developing DM by 2.65-fold (HR 2.65, 95\% Cl 2.5-2.8) after adjusting for age and sex. In model 3, each additional unit of TyG index was associated with a 3.81-fold higher risk of incident DM (HR 3.81, 95\% Cl 3.56-4.09). For sensitivity analysis, TyG index was transformed into a categorical variable (quartile of TyG index), and the $P$ value for the trend of TyG index with categorical variables was consistent with the result of TyG index as a continuous variable in the different models.

\section{Threshold Effect Analysis of TyG on Incident DM}

To evaluate whether a dose-response relationship between TyG index and incident DM existed, we used a smoothing function analysis. After adjusting for potential confounding factors, a nonlinear relationship between TyG index and DM was observed (Figure 2). The risk of developing DM was positively correlated with the TyG index. The risk of developing DM increases significantly with tyg until it peaks at 9.328 [HR 4.778 (4.179,5.462), $P<0.001]$. However, when the concentration of TyG index was higher than 
9.328, the hazard ratios for risk of developing DM was 2.61 (2.123,3.209),indicating that the risk of developing DM became gentle with an increase in TyG index $(P<0.001)$ (Table 3).

In the figure 2, the solidline curve indicates the estimated risk of incident DM, and the dotted lines represent point-wise 95\% confidence interval adjusted for age, sex, height, weight, LDL, TC, HDL-C, BUN, Ccr, AST, ALT, SBP, DBP, drinking status, smoking status and family history of diabetes.

\section{Subgroup Analyses}

To see if the association between TyG index and incident T2DM is stable in different subgroups, we did stratified analyses and interactive analyses (figure 3 ). The participants were divided into subgroups according to age, sex, HBP, BUN, smoking status, drinking status and family history of diabetes. The results showed that the association between TyG index and incident T2DM stably existed in the different subgroups. The additive interactions between TyG index and incident T2DM were observed in sex, age and BUN (P-value for interaction < 0.05).Stronger correlations were found in females or in participants with age $<65$ years, BUN $<7.1$.

\section{Discussion}

In this population-based cohort study, TyG index was found to be associated with an elevated risk of the incident DM in Chinese Obesity adult population, independent of age, sex, height, weight, LDL, TC, HDL-C, BUN, Ccr, AST, ALT, SBP, DBP, drinking status, smoking status and family history of diabetes.We further revealed a nonlinear relationship between TyG index and risk of incident DM. The relationship was characterized as follows: the risk of incident DM increased significantly with an increase in TyG index when the TyG index was less than 9.328 and the risk became gentle when the TyG index was beyond 9.328. The significant association was observed in the subgroups of sex, age and BUN.

T2DM is characterized by IR and decreased $\beta$-cell function[25-27]. In individuals with IR, insulin cannot function properly to stimulate glucose uptake. This condition is also associated with obesity and metabolic syndrome, characterized by central, visceral, and ectopic fat accumulation[28]. The storage of TG in nonadipose tissues, such as skeletal muscle, liver, pancreas, and heart, causes dysfunction at the cellular level and disruption of organ function[29]. Excess lipids may accumulate intercellularly and interfere with organ function through the paracrine effects of the released adipokines, whereas intracellular lipid deposition is associated with reduced insulin sensitivity[30]. Adipocyte dysfunction enhanced lipolysis, and free fatty acid (FFA) oxidation impairment results in a continuous oversupply of FFA and consequently lipid accumulation intracellularly[28, 31]. The FFA metabolites, including ceramides, diacylglycerol, and long-chain acylCoA, have deleterious effects on the cell and cause defects in insulin signaling[32]. High TG concentrations reduce glucokinase activity and glucose-stimulated insulin secretion in pancreatic islets, and high glucose levels cause islet cell destruction due to continuous oxidative stress[32]. Thus, glucose toxicity and lipotoxicity may exert an impact on $\beta$-cell failure[34].Simental-Mendía et al. proposed TyG index, which combines fasting triglycerides and fasting 
blood glucose[13]. In 748 apparently healthy participants, the sensitivity and specificity of TyG index for identifying IR were $84.0 \%$ and $45.0 \%$, respectively[13]. A systematic review and meta-analysis showed that the TyG index was significantly associated with an increased incidence of T2DM[30]. this is consistent with our findings with TyG index. Furthermore some studies have indicated that TyG index is associated with IR and proposed it as a reliable and useful surrogate indicator for identifying $\operatorname{IR}[11,14$, $21,35]$.A cohort study with 11,113 nondiabetic participants in rural Chinese followed for 6 years firstly showed that, compared to participants in the lowest quartile of TyG, participants in the highest quartile of TyG had a higher risk of diabetes (relative risk $3.54 ; 95 \% \mathrm{Cl} 2.08-6.03$ ) after adjusting for age, family history of diabetes, family history of hypertension, education level, marital status, smoking, alcohol consumption, physical activity and SBP[36]. They found that the association was stable in both men and women(HR 3.54, 95\% Cl 2.08-6.03 for men; HR 6.15, 95\% Cl 3.48-10.85 for women; P for interaction < 0.001)[36].Also, in a cohort of 4820 White Europeans had similar results both in men and women[37].These conclusions are consistent with our findings (TyG as continuous variable: HR 3.61, 95\% $\mathrm{Cl}$ 3.34-3.91 for men; $\mathrm{HR} 4.91,95 \% \mathrm{Cl}$ 4.2-5.73 for women; $\mathrm{P}$ for interaction $=0.006$ ). A meta regression analysis showed that the correlation between TyG index and T2DM incidence was affected by baseline age (coefficient: $-0.05, p=0.015$ )[37]. This also agrees with our study.खHR 3.85, 95\% I 3.57-4.16 for age $<65$; HR $3.14,95 \% \mathrm{Cl} 2.64-3.73$ for age $>65$; $\mathrm{P}$ for interaction $=0.001)$. One of the possible explanations is that as age increases, TyG index became less influential for determining the risk of T2DM[30].

However, compared with previous studies, although TyG was positively associated with an increased risk of T2DM after adjusting for confounding factors. But there are still some conclusions different from our study.We assessed the dose-response relation- ship between TyG index and risk of T2DM and found that there was a nonlinear association with a turning point 9.328 of TyG index:the risk of developing DM increased significantly with an increase in TyG index when the TyG index was less than 9.328 and the risk became gentle when the TyG index was beyond 9.328.But,a meta-analysis[30], which included 270,229 subjects from 14 cohort studies, found the dose-response curve became increasingly steeper at TyG index above 8.6.This may be attributed to our study population being obese, which is a major risk factor for diabetes development. Obesity patients are often accompanied with fat metabolism, high TG concentrations reduce glucokinase activity and glucose-stimulated insulin secretion in pancreatic islets, and high glucose levels cause islet cell destruction due to continuous oxidative stress[33, 38, 39]. After the lipid and glucose metabolism abnormalities reach to some extent, the impact of the tyg index may be weakened.Another article suggests that tyg index had a linear relationship with diabetes $₫$ But the number of cases was only 12723 and our study was 80919; and the population was Japanese adults. The relationship between tyg index and diabetes varies between races[33, 38, 39]. And the dietary structure may vary between the Japanese and the Chinese, so there is a gap with our research[41].Our study has severalstrengths. (1) Compared to previous similar studies, our study had arelatively large sample size. (2) The correlation between TyG index and T2DM was performed in Chinese Obesity adult population for the first time. (3) To decrease the result contingency and 
elevate the robustness ofthe results, TyG was treated both as a continuous and categoricalvariable. (4) In the subgroup analysis, we used stratified linear regressionmodels and likelihood ration tests to find modifications and interactions andto obtain stable results in different subgroups. (5) We used the Cox proportional hazards regression model with cubic spline functions to estimated the nonlinear relationship between TyG and DM.

Our study also has some limitations.First, the study sample is selected from China, which may hamper the representativeness of study results. However, One quarter of diabetics live in China, and our data comes from multiple centers in China with a wide geographical and age range, which makes the results widely applicable to the Chinese population and even Chinese around the world.Second, In this study, we did not distinguish between type 1 diabetes and type 2 diabetes. However, since type 2 diabetes accounts for about $95 \%$ of all diabetes cases, our findings may be more representative of type 2 diabetes[42].Third,

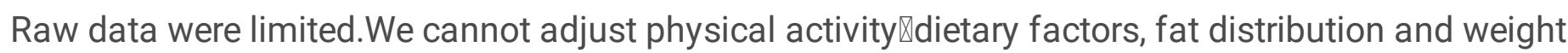
changes which may affect the relationship between TyG index and T2DM. However, our results remain stable after multiple adjustments of the correlation variables.

\section{Conclusion}

In conclusion, an increase of TyG index was independently associated with a higher incidence of diabetes mellitus in this prospective study during 6-year follow-up of Chinese Obesity adult population, independent of age, sex, height, weight, LDL, TC, HDL-C, BUN, Ccr, AST, ALT, SBP, DBP, drinking status, smoking status and family history of diabetes. A positive curvilinear association between GGT and incident diabetes mellitus was present, with a saturation effect predicted at 9.328 of TyG index.

\section{Abbreviations}

T2DM: Type 2 diabetes mellitus

IR: Insulin resistance

TyG index: Triglyceride-glucose index

BMI: Body mass index

HDL-C: High-density lipoprotein cholesterol

TC: Total cholesterol

TG: Triglycerides

SBP: Systolic blood pressure

DBP: Diastolic blood pressure 


\section{Declarations}

Acknowledgments

The author is very grateful to the data providers of the study. They completed the entire study. They are Ying Chen, Xiao-Ping Zhang, Jie Yuan, Bo Cai, Xiao-Li Wang, Xiao-Li Wu,Yue-Hua Zhang, Xiao-Yi Zhang, Tong Yin, Xiao-Hui Zhu, Yun-Juan Gu,Shi-Wei Cui, Zhi-Qiang Lu, Xiao-Ying Li (corresponding author) (the rankings of these researchers were ranked according to reference [23]).

\section{Authors' contributions}

The author designed the research, analysised the data and drafted the manuscript by himself.

\section{Ethics approval and consent to participate}

Not applicable

\section{Funding}

None

\section{Availability of data and material}

Data can be downloaded from the DRYAD database (http:// www.Datadryad.org).

\section{Competing interests}

The author declares no conflicts of interest in this work.

\section{Consent to publication}

Not applicable/all data used for the present study have been anonymized, and the submission does not include information that may identify individual persons.

\section{References}

1. Yoon KH, Lee JH, Kim JW, Cho JH, Choi YH, Ko SH, Zimmet P, Son HY: Epidemic obesity and type 2 diabetes in Asia. LANCET 2006, 368(9548):1681-1688.

2. Cardiovascular disease, chronic kidney disease, and diabetes mortality burden of cardiometabolic risk factors from 1980 to 2010: a comparative risk assessment. Lancet Diabetes Endocrinol 2014, 2(8):634-647.

3. Seuring T, Archangelidi O, Suhrcke M: The Economic Costs of Type 2 Diabetes: A Global Systematic Review. PHARMACOECONOMICS 2015, 33(8):811-831. 
4. Shaw JE, Sicree RA, Zimmet PZ: Global estimates of the prevalence of diabetes for $\mathbf{2 0 1 0}$ and 2030. Diabetes Res Clin Pract 2010, 87(1):4-14.

5. Worldwide trends in diabetes since 1980: a pooled analysis of 751 population-based studies with 4.4 million participants. LANCET 2016, 387(10027):1513-1530.

6. Wang L, Gao P, Zhang M, Huang Z, Zhang D, Deng Q, Li Y, Zhao Z, Qin X, Jin D et al: Prevalence and Ethnic Pattern of Diabetes and Prediabetes in China in 2013. JAMA 2017, 317(24):2515-2523.

7. Warram JH, Martin BC, Krolewski AS, Soeldner JS, Kahn CR: Slow glucose removal rate and hyperinsulinemia precede the development of type II diabetes in the offspring of diabetic parents. $A N N$ INTERN MED 1990, 113(12):909-915.

8. Defronzo RA: Banting Lecture. From the triumvirate to the ominous octet: a new paradigm for the treatment of type 2 diabetes mellitus. DIABETES 2009, 58(4):773-795.

9. Scheen AJ: Pathophysiology of type 2 diabetes. ACTA CLIN BELG 2003, 58(6):335-341.

10. DeFronzo RA, Tobin JD, Andres R: Glucose clamp technique: a method for quantifying insulin secretion and resistance. Am J Physiol 1979, 237(3):E214-E223.

11. Guerrero-Romero F, Simental-Mendia LE, Gonzalez-Ortiz M, Martinez-Abundis E, Ramos-Zavala MG, Hernandez-Gonzalez SO, Jacques-Camarena O, Rodriguez-Moran M: The product of triglycerides and glucose, a simple measure of insulin sensitivity. Comparison with the euglycemic-hyperinsulinemic clamp. J Clin Endocrinol Metab 2010, 95(7):3347-3351.

12. Abbasi F, Reaven GM: Comparison of two methods using plasma triglyceride concentration as a surrogate estimate of insulin action in nondiabetic subjects: triglycerides $\mathrm{x}$ glucose versus triglyceride/high-density lipoprotein cholesterol. METABOLISM 2011, 60(12):1673-1676.

13. Simental-Mendia LE, Rodriguez-Moran M, Guerrero-Romero F: The product of fasting glucose and triglycerides as surrogate for identifying insulin resistance in apparently healthy subjects. Metab Syndr Relat Disord 2008, 6(4):299-304.

14. Vasques AC, Novaes FS, de Oliveira MS, Souza JR, Yamanaka A, Pareja JC, Tambascia MA, Saad MJ, Geloneze B: TyG index performs better than HOMA in a Brazilian population: a hyperglycemic clamp validated study. Diabetes Res Clin Pract 2011, 93(3):e98-e100.

15. Guerrero-Romero F, Villalobos-Molina R, Jimenez-Flores JR, Simental-Mendia LE, Mendez-Cruz R, Murguia-Romero M, Rodriguez-Moran M: Fasting Triglycerides and Glucose Index as a Diagnostic Test for Insulin Resistance in Young Adults. ARCH MED RES 2016, 47(5):382-387.

16. Mazidi M, Kengne AP, Katsiki N, Mikhailidis DP, Banach M: Lipid accumulation product and triglycerides/glucose index are useful predictors of insulin resistance. J Diabetes Complications 2018, 
17. Zhang M, Wang B, Liu Y, Sun X, Luo X, Wang C, Li L, Zhang L, Ren Y, Zhao Y et al: Cumulative increased risk of incident type 2 diabetes mellitus with increasing triglyceride glucose index in normalweight people: The Rural Chinese Cohort Study. CARDIOVASC DIABETOL 2017, 16(1):30.

18. Lee SH, Kwon HS, Park YM, Ha HS, Jeong SH, Yang HK, Lee JH, Yim HW, Kang MI, Lee WC et al: Predicting the development of diabetes using the product of triglycerides and glucose: the Chungju Metabolic Disease Cohort (CMC) study. PLOS ONE 2014, 9(2):e90430.

19. Lee JW, Lim NK, Park HY: The product of fasting plasma glucose and triglycerides improves risk prediction of type 2 diabetes in middle-aged Koreans. BMC ENDOCR DISORD 2018, 18(1):33.

20. Low S, Khoo K, Irwan B, Sum CF, Subramaniam T, Lim SC, Wong T: The role of triglyceride glucose index in development of Type 2 diabetes mellitus. Diabetes Res Clin Pract 2018, 143:43-49.

21. Park B, Lee HS, Lee YJ: Triglyceride glucose (TyG) index as a predictor of incident type 2 diabetes among nonobese adults: a 12-year longitudinal study of the Korean Genome and Epidemiology Study cohort. TRANSL RES2021, 228:42-51.

22. Ke P, Wu X, Xu M, Feng J, Xu H, Gan Y, Wang C, Deng Z, Liu X, Fu W et al: Comparison of obesity indices and triglyceride glucose-related parameters to predict type 2 diabetes mellitus among normalweight elderly in China. Eat Weight Disord 2021.

23. Chen $Y$, Zhang XP, Yuan J, Cai B, Wang XL, Wu XL, Zhang YH, Zhang XY, Yin T, Zhu XH et al: Association of body mass index and age with incident diabetes in Chinese adults: a population-based cohort study. BMJ OPEN 2018, 8(9):e21768.

24. White IR, Royston P, Wood AM: Multiple imputation using chained equations: Issues and guidance for practice. STAT MED 2011, 30(4):377-399.

25. Zheng Y, Ley SH, Hu FB: Global aetiology and epidemiology of type 2 diabetes mellitus and its complications. NAT REV ENDOCRINOL 2018, 14(2):88-98.

26. Kahn SE: The relative contributions of insulin resistance and beta-cell dysfunction to the pathophysiology of Type 2 diabetes. DIABETOLOGIA 2003, 46(1):3-19.

27. Alejandro EU, Gregg B, Blandino-Rosano M, Cras-Meneur C, Bernal-Mizrachi E: Natural history of beta-cell adaptation and failure in type 2 diabetes. MOL ASPECTS MED 2015, 42:19-41.

28. Snel M, Jonker JT, Schoones J, Lamb H, de Roos A, Pijl H, Smit JW, Meinders AE, Jazet IM: Ectopic fat and insulin resistance: pathophysiology and effect of diet and lifestyle interventions. INT J ENDOCRINOL 2012, 2012:983814. 
29. Ferrara D, Montecucco F, Dallegri F, Carbone F: Impact of different ectopic fat depots on cardiovascular and metabolic diseases. J CELL PHYSIOL 2019, 234(12):21630-21641.

30. Pranata R, Huang I, Irvan, Lim MA, Vania R: The association between triglyceride-glucose index and the incidence of type 2 diabetes mellitus-a systematic review and dose-response meta-analysis of cohort studies. ENDOCRINE 2021.

31. Samuel VT, Shulman GI: The pathogenesis of insulin resistance: integrating signaling pathways and substrate flux. J CLIN INVEST 2016, 126(1):12-22.

32. Morino K, Petersen KF, Shulman GI: Molecular mechanisms of insulin resistance in humans and their potential links with mitochondrial dysfunction. DIABETES 2006, 55 Suppl 2:S9-S15.

33. Liu EQ, Weng YP, Zhou AM, Zeng CL: Association between Triglyceride-Glucose Index and Type 2 Diabetes Mellitus in the Japanese Population: A Secondary Analysis of a Retrospective Cohort Study. BIOMED RES INT 2020, 2020:2947067.

34. DeFronzo RA, Ferrannini E, Groop L, Henry RR, Herman WH, Holst JJ, Hu FB, Kahn CR, Raz I, Shulman GI et al: Type 2 diabetes mellitus. NAT REV DIS PRIMERS 2015, 1:15019.

35. Du T, Yuan G, Zhang M, Zhou X, Sun X, Yu X: Clinical usefulness of lipid ratios, visceral adiposity indicators, and the triglycerides and glucose index as risk markers of insulin resistance. CARDIOVASC DIABETOL 2014, 13:146.

36. Wang B, Zhang M, Liu Y, Sun X, Zhang L, Wang C, Li L, Ren Y, Han C, Zhao Y et al: Utility of three novel insulin resistance-related lipid indices for predicting type 2 diabetes mellitus among people with normal fasting glucose in rural China. J DIABETES 2018, 10(8):641-652.

37. Navarro-Gonzalez D, Sanchez-Inigo L, Pastrana-Delgado J, Fernandez-Montero A, Martinez JA: Triglyceride-glucose index (TyG index) in comparison with fasting plasma glucose improved diabetes prediction in patients with normal fasting glucose: The Vascular-Metabolic CUN cohort. PREV MED 2016, 86:99-105.

38. Unger RH: Lipotoxicity in the pathogenesis of obesity-dependent NIDDM. Genetic and clinical implications. DIABETES 1995, 44(8):863-870.

39. Robertson RP, Harmon J, Tran PO, Poitout V: Beta-cell glucose toxicity, lipotoxicity, and chronic oxidative stress in type 2 diabetes. DIABETES 2004, 53 Suppl 1:S119-S124.

40. Janghorbani M, Almasi SZ, Amini M: The product of triglycerides and glucose in comparison with fasting plasma glucose did not improve diabetes prediction. ACTA DIABETOL 2015, 52(4):781-788.

41. Trouwborst I, Bowser SM, Goossens GH, Blaak EE: Ectopic Fat Accumulation in Distinct Insulin Resistant Phenotypes; Targets for Personalized Nutritional Interventions. Front Nutr 2018, 5:77. 


\section{Tables}

Page $13 / 22$ 
Table 1: Baseline characteristics of study participants according to quartiles of TyG.

\begin{tabular}{|c|c|c|c|c|c|c|}
\hline TyG & Overall & Q1 & Q2 & Q3 & Q4 & $\begin{array}{l}\mathrm{P} \text { - } \\
\text { value }\end{array}$ \\
\hline Number & 80919 & 20228 & 20212 & 20249 & 20230 & \\
\hline Age (years) & $\begin{array}{l}45.1 \pm \\
13.0\end{array}$ & $\begin{array}{l}42.3 \pm \\
12.4\end{array}$ & $\begin{array}{l}44.9 \pm \\
13.3\end{array}$ & $\begin{array}{l}46.2 \pm \\
13.3\end{array}$ & $\begin{array}{l}47.0 \pm \\
12.6\end{array}$ & $\begin{array}{l}<.001 \\
0.001\end{array}$ \\
\hline Height(cm) & $\begin{array}{l}167.9 \pm \\
8.4\end{array}$ & $\begin{array}{l}166.6 \pm \\
8.6\end{array}$ & $\begin{array}{l}167.7 \pm \\
8.4\end{array}$ & $\begin{array}{l}168.4 \pm \\
8.3\end{array}$ & $\begin{array}{l}169.1 \pm \\
7.9\end{array}$ & $\begin{array}{l}< \\
0.001\end{array}$ \\
\hline Weight(kg) & $\begin{array}{l}75.2 \pm \\
10.1\end{array}$ & $72.4 \pm 9.3$ & $74.4 \pm 9.7$ & $\begin{array}{l}76.1 \pm \\
10.2\end{array}$ & $\begin{array}{l}77.7 \pm \\
10.3\end{array}$ & $\begin{array}{l}< \\
0.001\end{array}$ \\
\hline BMI (kg/m2) & $26.6 \pm 2.2$ & $26.0 \pm 1.9$ & $26.4 \pm 2.1$ & $26.8 \pm 2.3$ & $27.1 \pm 2.4$ & $\begin{array}{l}<.001 \\
0.001\end{array}$ \\
\hline $\mathrm{SBP}(\mathrm{mmHg})$ & $\begin{array}{l}125.3 \pm \\
16.3\end{array}$ & $\begin{array}{l}121.5 \pm \\
15.5\end{array}$ & $\begin{array}{l}124.4 \pm \\
15.9\end{array}$ & $\begin{array}{l}126.6 \pm \\
16.4\end{array}$ & $\begin{array}{l}128.6 \pm \\
16.7\end{array}$ & $\begin{array}{l}< \\
0.001\end{array}$ \\
\hline $\mathrm{DBP}(\mathrm{mmHg})$ & $\begin{array}{l}78.1 \pm \\
11.0\end{array}$ & $\begin{array}{l}75.2 \pm \\
10.6\end{array}$ & $\begin{array}{l}77.4 \pm \\
10.8\end{array}$ & $\begin{array}{l}79.0 \pm \\
10.9\end{array}$ & $\begin{array}{l}80.8 \pm \\
11.1\end{array}$ & $\stackrel{<}{<.001}$ \\
\hline $\mathrm{FPG}(\mathrm{mmol} / \mathrm{L})$ & $5.1 \pm 0.6$ & $4.8 \pm 0.6$ & $5.0 \pm 0.6$ & $5.1 \pm 0.6$ & $5.3 \pm 0.6$ & $\begin{array}{l}< \\
0.001\end{array}$ \\
\hline $\mathrm{TC}(\mathrm{mmol} / \mathrm{L})$ & $4.9 \pm 0.9$ & $4.5 \pm 0.8$ & $4.8 \pm 0.8$ & $5.0 \pm 0.9$ & $5.3 \pm 1.0$ & $\begin{array}{l}< \\
0.001\end{array}$ \\
\hline $\mathrm{TG}(\mathrm{mmol} / \mathrm{L})$ & $1.8 \pm 1.3$ & $0.8 \pm 0.2$ & $1.2 \pm 0.2$ & $1.8 \pm 0.3$ & $3.3 \pm 1.7$ & $\hat{0}_{0.001}$ \\
\hline TyG index & $8.7 \pm 0.6$ & $8.0 \pm 0.3$ & $8.5 \pm 0.1$ & $8.9 \pm 0.1$ & $9.5 \pm 0.4$ & $\begin{array}{l}<.001 \\
0.001\end{array}$ \\
\hline $\mathrm{HDL}-\mathrm{C}(\mathrm{mmol} / \mathrm{L})$ & $1.3 \pm 0.3$ & $1.4 \pm 0.3$ & $1.3 \pm 0.3$ & $1.3 \pm 0.3$ & $1.2 \pm 0.3$ & $\begin{array}{l}< \\
0.001\end{array}$ \\
\hline $\mathrm{LDL}(\mathrm{mmol} / \mathrm{L})$ & $2.9 \pm 0.7$ & $2.7 \pm 0.6$ & $2.9 \pm 0.6$ & $3.0 \pm 0.7$ & $3.0 \pm 0.8$ & $\begin{array}{l}<.001 \\
0.001\end{array}$ \\
\hline $\operatorname{ALT}(\mathrm{U} / \mathrm{L})$ & $\begin{array}{l}31.8 \pm \\
25.9\end{array}$ & $\begin{array}{l}24.8 \pm \\
24.3\end{array}$ & $\begin{array}{l}29.3 \pm \\
23.4\end{array}$ & $\begin{array}{l}33.6 \pm \\
25.3\end{array}$ & $\begin{array}{l}39.4 \pm \\
28.0\end{array}$ & $\dot{0} 001$ \\
\hline AST(U/L) & $\begin{array}{l}26.7 \pm \\
12.6\end{array}$ & $\begin{array}{l}24.2 \pm \\
12.2\end{array}$ & $\begin{array}{l}25.7 \pm \\
13.0\end{array}$ & $\begin{array}{l}27.4 \pm \\
12.0\end{array}$ & $\begin{array}{l}29.8 \pm \\
12.7\end{array}$ & $\begin{array}{l}< \\
0.001\end{array}$ \\
\hline $\mathrm{BUN}(\mathrm{mmol} / \mathrm{L})$ & $4.8 \pm 1.2$ & $4.8 \pm 1.2$ & $4.8 \pm 1.2$ & $4.9 \pm 1.2$ & $4.9 \pm 1.2$ & $\begin{array}{l}< \\
0.001\end{array}$ \\
\hline Follow-up\year》 & $3.1 \pm 0.9$ & $3.2 \pm 1.0$ & $3.1 \pm 0.9$ & $3.1 \pm 0.9$ & $3.1 \pm 0.9$ & $\begin{array}{l}<.001 \\
0.00\end{array}$ \\
\hline Ccr(umol/L) & $\begin{array}{l}74.4 \pm \\
15.7\end{array}$ & $\begin{array}{l}71.5 \pm \\
16.5\end{array}$ & $\begin{array}{l}73.9 \pm \\
15.8\end{array}$ & $\begin{array}{l}75.4 \pm \\
14.9\end{array}$ & $\begin{array}{l}76.9 \pm \\
14.9\end{array}$ & $\begin{array}{l}< \\
0.001\end{array}$ \\
\hline
\end{tabular}


$\operatorname{Sex}(\%)$

\begin{tabular}{llllll}
\hline Male & 58470 & 12059 & 14217 & 15472 & $\begin{array}{l}16722 \\
(82.7)\end{array}$ \\
& $(72.3)$ & $(59.6)$ & $(70.3)$ & $(76.4)$ & \\
Female & 22449 & 8169 & 5995 & 4777 & 3508 \\
& $(27.7)$ & $(40.4)$ & $(29.7)$ & $(23.6)$ & $(17.3)$
\end{tabular}

developed DM(\%)

\begin{tabular}{llllll} 
No & $\begin{array}{llll}77911 \\
(96.3)\end{array}$ & $\begin{array}{l}19996 \\
(98.9)\end{array}$ & $\begin{array}{l}19738 \\
(97.7)\end{array}$ & $\begin{array}{l}19447 \\
(96)\end{array}$ & $\begin{array}{l}18730 \\
(92.6)\end{array}$ \\
\hline Yes & 3008( & $232(1.1)$ & $474(2.3)$ & $802(4)$ & $1500(7.4)$ \\
& $3.7)$ & & & & \\
\hline
\end{tabular}

\section{$\mathrm{HBP}(\%)$}

No
Yes
Smoking status (\%)

Current

\section{1}

(26.2)

Ever

1325(

$$
\text { 5.4) }
$$

Never

16635
$(68.4)$

(68.4)
19289

(95.4)

939 (4.6)

6387
$7.9)$

18838

(93.2)

$1374(6.8)$
$<$

0.001

<.001

\section{8}

(91.2)

17937

(88.7)

2293

(11.3)

\section{Drinking status(\%)}

\section{Current}

Ever

Never

Family history of diabetes(\%)

No

\begin{tabular}{lllll}
$787(3.2)$ & $111(2.1)$ & $172(2.9)$ & $199(3.1)$ & $305(4.6)$ \\
$\begin{array}{l}4709 \\
(19.4)\end{array}$ & $888(16.9)$ & $\begin{array}{l}1130 \\
(18.7)\end{array}$ & $\begin{array}{l}1234 \\
(19.4)\end{array}$ & $\begin{array}{l}1457 \\
(21.8)\end{array}$ \\
$\begin{array}{l}18835 \\
(77.4)\end{array}$ & $4246(81)$ & $\begin{array}{l}4728 \\
(78.4)\end{array}$ & $\begin{array}{l}4925 \\
(77.5)\end{array}$ & $\begin{array}{l}4936 \\
(73.7)\end{array}$ \\
\hline
\end{tabular}

\begin{tabular}{|llll}
$870(16.6)$ & $\begin{array}{l}1381 \\
(22.9)\end{array}$ & $\begin{array}{l}1761 \\
(27.7)\end{array}$ & $\begin{array}{l}2359 \\
(35.2)\end{array}$ \\
\hline $249(4.7)$ & $351(5.8)$ & $344(5.4)$ & $381(5.7)$
\end{tabular}

$\begin{array}{llll}4126 & 4298 & 4253 & 3958 \\ (78.7) & (71.3) & (66.9) & (59.1)\end{array}$
3958
$(59.1)$ 
BMI: body mass index; HDL-C: high-density lipoprotein cholesterol; FPG: fasting plasma glucose; TC: total cholesterol; TG: triglyceride; SBP: systolic blood pressure; DBP: diastolic blood pressure; TyG: triglyceride-glucose index; CCR: concentration of creatinine; AST: aspartate aminotransferase; ALT: alanine aminotransferase; BUN: blood urea nitrogen, T2DM: type 2 diabetes mellitus; Cl: confidence interval; HR: hazard ratio. 
Table 2: Univariate analysis for type 2 diabetes mellitus.

\begin{tabular}{|c|c|c|}
\hline & $\mathrm{HR}(95 \% \mathrm{Cl})$ & P-value \\
\hline Age (years) & $1.05(1.05,1.05)$ & $<0.001$ \\
\hline Height(cm) & $0.99(0.99,0.99)$ & $<0.001$ \\
\hline Weight(kg) & $1.02(1.02,1.03)$ & $<0.001$ \\
\hline BMI (kg/m2) & $1.17(1.16,1.19)$ & $<0.001$ \\
\hline $\mathrm{SBP}(\mathrm{mmHg})$ & $1.03(1.02,1.03)$ & $<0.001$ \\
\hline $\mathrm{DBP}(\mathrm{mmHg})$ & $1.03(1.02,1.03)$ & $<0.001$ \\
\hline $\mathrm{FPG}(\mathrm{mmol} / \mathrm{L})$ & $7.69(7.29,8.1)$ & $<0.001$ \\
\hline $\mathrm{TC}(\mathrm{mmol} / \mathrm{L})$ & $1.19(1.14,1.23)$ & $<0.001$ \\
\hline $\mathrm{TG}(\mathrm{mmol} / \mathrm{L})$ & $1.17(1.16,1.19)$ & $<0.001$ \\
\hline TyG index & $2.83(2.69,2.99)$ & $<0.001$ \\
\hline $\mathrm{HDL}-\mathrm{C}(\mathrm{mmol} / \mathrm{L})$ & $1.29(1.1,1.5)$ & 0.002 \\
\hline $\operatorname{LDL}(\mathrm{mmol} / \mathrm{L})$ & $1.07(1.01,1.14)$ & 0.027 \\
\hline $\operatorname{ALT}(\mathrm{U} / \mathrm{L})$ & $1.0045(1.0038,1.0051)$ & $<0.001$ \\
\hline AST(U/L) & $1.0051(1.0038,1.0064)$ & $<0.001$ \\
\hline $\mathrm{BUN}(\mathrm{mmol} / \mathrm{L})$ & $1.12(1.08,1.15)$ & $<0.001$ \\
\hline Ccr(umol/L) & $0.9988(0.9964,1.0012)$ & 0.335 \\
\hline \multicolumn{3}{|l|}{ Sex (\%) } \\
\hline Male & Ref & \\
\hline Female & $0.87(0.8,0.95)$ & 0.001 \\
\hline \multicolumn{3}{|l|}{$\mathrm{HBP}(\%)$} \\
\hline No & Ref & \\
\hline Yes & $2.1(1.9,2.33)$ & $<0.001$ \\
\hline \multicolumn{3}{|c|}{ Smoking status (\%) } \\
\hline Current & Ref & \\
\hline Ever & $0.88(0.68,1.16)$ & 0.364 \\
\hline Never & $0.58(0.51,0.67)$ & $<0.001$ \\
\hline
\end{tabular}




\begin{tabular}{lll} 
Ever & $0.51(0.37,0.72)$ & $<0.001$ \\
\hline Never & $0.58(0.43,0.8)$ & $<0.001$
\end{tabular}

Family history of diabetes(\%)

No Ref

Yes

$<0.001$

BMI: body mass index; HDL-C: high-density lipoprotein cholesterol; FPG: fasting plasma glucose; TC: total cholesterol; TG: triglyceride; SBP: systolic blood pressure; DBP: diastolic blood pressure; TyG: triglyceride-glucose index; CCR: concentration of creatinine; AST: aspartate aminotransferase; ALT: alanine aminotransferase; BUN: blood urea nitrogen, T2DM: type 2 diabetes mellitus; Cl: confidence interval; HR: hazard ratio.

Table 3: Relationship between TyG and incident diabetes mellitus in different models.

\begin{tabular}{|c|c|c|c|c|c|c|}
\hline Variable & model 1 & & model 2 & & model 3 & \\
\hline & $\mathrm{HR}(95 \% \mathrm{Cl})$ & $P$ value & $\mathrm{HR}(95 \% \mathrm{Cl})$ & $P$ value & $\mathrm{HR}(95 \% \mathrm{Cl})$ & $P$ value \\
\hline TyG & $\begin{array}{l}2.83 \\
(2.69,2.99)\end{array}$ & $<0.001$ & $2.65(2.5,2.8)$ & $<0.001$ & $\begin{array}{l}3.81 \\
(3.56,4.09)\end{array}$ & $<0.001$ \\
\hline \multicolumn{7}{|l|}{$\begin{array}{l}\text { TyG } \\
\text { levels }\end{array}$} \\
\hline Q1 & Ref & & Ref & & Ref & \\
\hline Q2 & $2.2(1.88,2.58)$ & $<0.001$ & $\begin{array}{l}1.92 \\
(1.64,2.25)\end{array}$ & $<0.001$ & $\begin{array}{l}2.03 \\
(1.73,2.38)\end{array}$ & $<0.001$ \\
\hline Q3 & $\begin{array}{l}3.83 \\
(3.31,4.44)\end{array}$ & $<0.001$ & $\begin{array}{l}3.16 \\
(2.72,3.66)\end{array}$ & $<0.001$ & $\begin{array}{l}3.51 \\
(3.02,4.09)\end{array}$ & $<0.001$ \\
\hline Q4 & $\begin{array}{l}7.27 \\
(6.33,8.35)\end{array}$ & $<0.001$ & $\begin{array}{l}5.81 \\
(5.05,6.68)\end{array}$ & $<0.001$ & $7.31(6.29,8.5)$ & $<0.001$ \\
\hline $\begin{array}{l}\text { P for } \\
\text { trend }\end{array}$ & & $<0.001$ & & $<0.001$ & & $<0.001$ \\
\hline
\end{tabular}

Model 1 was not adjusted. Model 2 was adjusted for age and sex. Model 3 was adjusted for age, sex, height, weight, LDL, TC,HDL-C,BUN, CCR, AST, ALT, SBP, DBP, drinking status, smoking status and family history of diabetes. TyG: triglyceride-glucose index. 
Table 4: Threshold effect analysis of TyG on incident diabetes mellitus

\begin{tabular}{lll} 
Outcome: & $\mathrm{HR}(95 \% \mathrm{Cl})$ & P value \\
\hline One-line linear regression model & $3.81(3.56,4.09)$ & $<0.001$ \\
\hline Two-piecewise linear regression model & & \\
\hline TyG<9.328 & $4.778(4.179,5.462)$ & $<0.001$ \\
\hline TyG $>=9.328$ & $2.61(2.123,3.209)$ & $<0.001$ \\
\hline Log-likelihood ratio test & & $<0.001$ \\
\hline
\end{tabular}

Notes: adjusted for age, sex, height, weight, LDL, TC,HDL-C,BUN, Ccr, AST, ALT, SBP, DBP, drinking status, smoking status and family history of diabetes.

\section{Figures}




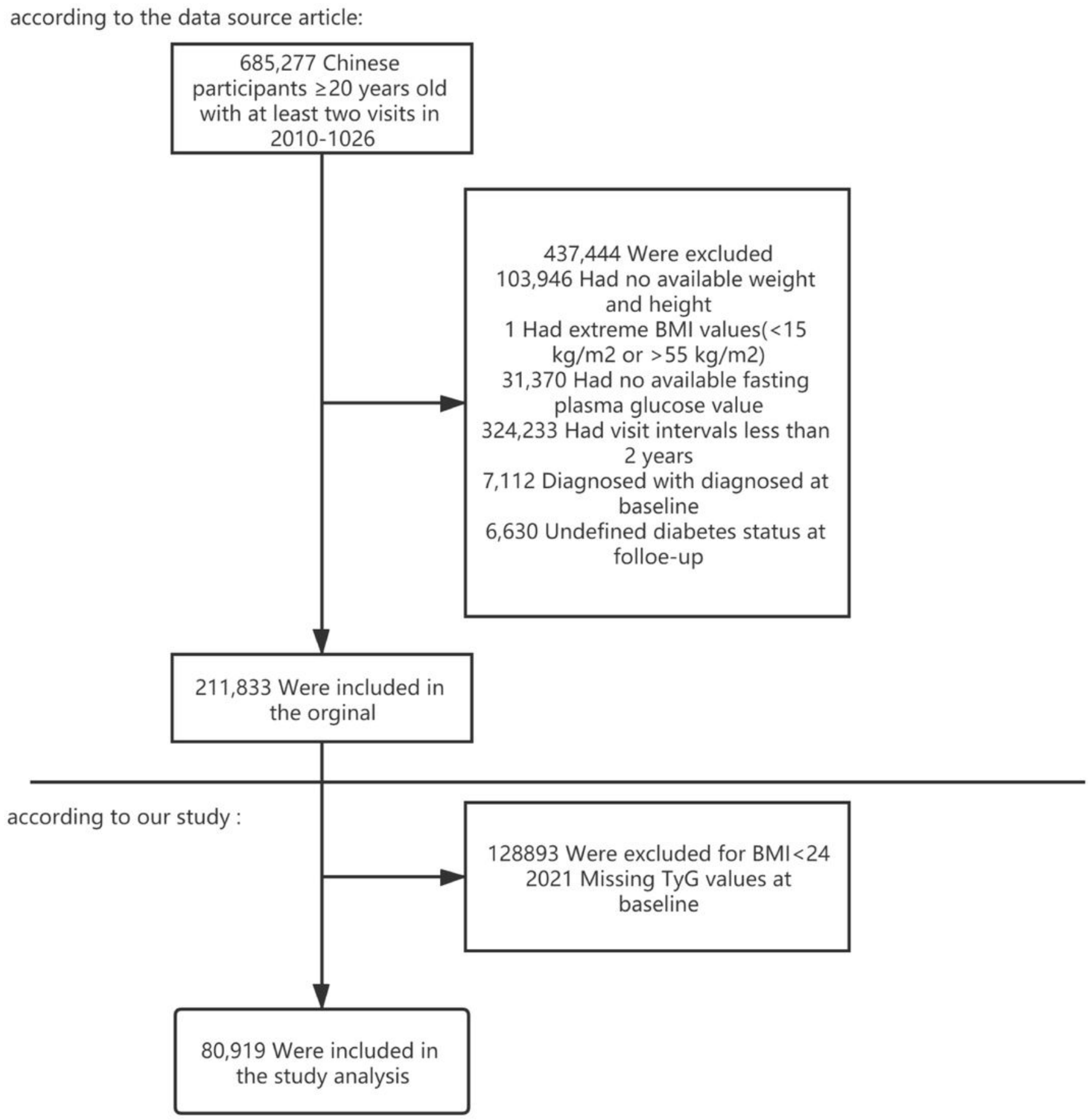

\section{Figure 1}

Flowchart of study participants. 


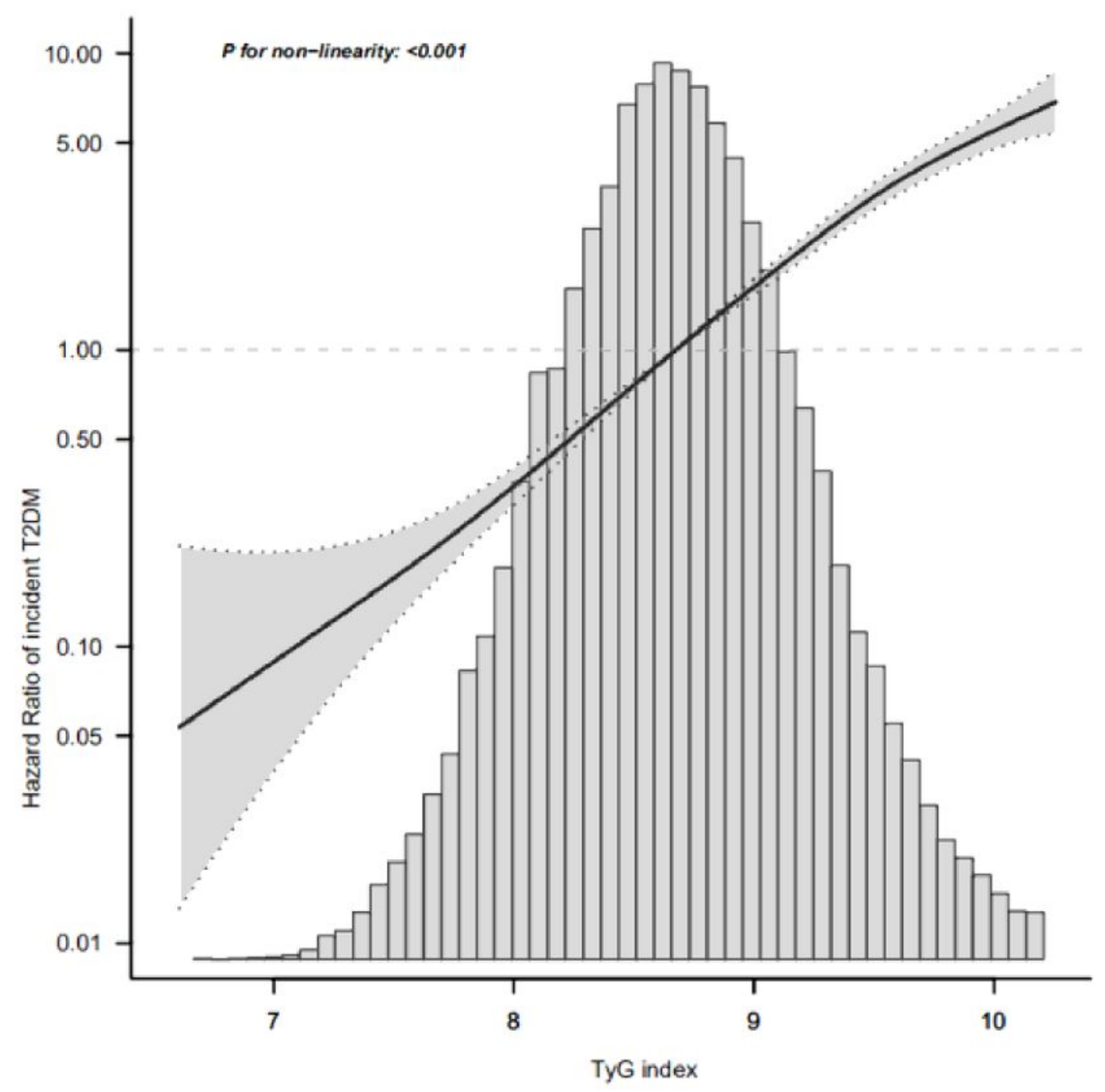

Figure 2

Fitting a curve for incident T2DM according to the TyG index adjust for age, sex, height, weight, LDL, TC, HDL-C, BUN, Ccr, AST, ALT, SBP, DBP, drinking status, smoking status and family history of diabetes. 


\begin{tabular}{|c|c|c|c|c|c|}
\hline Subgroup & n.total & n.event_\% & HR_95CI & & P.for.interaction \\
\hline $\operatorname{Sex}$ & & & & & 0.006 \\
\hline Male & 58470 & $2296(3.9)$ & $3.61(3.34,3.91)$ & & \\
\hline Female & 22449 & $712(3.2)$ & $4.91(4.2,5.73)$ & & \\
\hline Age & & & & & 0.001 \\
\hline$<65$ & 73647 & $2388(3.2)$ & $3.85(3.57 .4 .16)$ & & \\
\hline$=65$ & 7272 & $620(8.5)$ & $3.14(2.64,3.73)$ & & \\
\hline BUN & & & & & 0.037 \\
\hline$<7.1$ & 77537 & $2826(3.6)$ & $3.89(3.62 .4 .18)$ & & \\
\hline$=7.1$ & 3382 & $182(5.4)$ & $2.67(2.02,3.53)$ & & \\
\hline HBP & & & & & 0.345 \\
\hline No & 74532 & $2559(3.4)$ & $3.88(3.6 .4 .19)$ & & \\
\hline Yes & 6387 & $449(7)$ & $3.25(2.7,3.9)$ & & \\
\hline Smoking Status & & & & & 0.08 \\
\hline Current & 19268 & $1004(5.2)$ & $3.37(3,3.8)$ & & \\
\hline Ever & 3974 & $200(5)$ & $3.79(2.95,4.89)$ & & \\
\hline Never & 57677 & $1804(3.1)$ & $4.13(3.76 .4 .54)$ & & \\
\hline Drinking Status & & & & & 0.906 \\
\hline Current & 2429 & $137(5.6)$ & $3.6(2.58,5.03)$ & & \\
\hline Ever & 14149 & $513(3.6)$ & $3.68(3.16,4.29)$ & & \\
\hline Never & 64341 & $2358(3.7)$ & $3.89(3.59 .4 .23)$ & & \\
\hline Family histroy of diabetes & & & & & 0.078 \\
\hline No & 79272 & $2894(3.7)$ & $3.86(3.6,4.14)$ & & \\
\hline Yes & 1647 & $114(6.9)$ & $2.99(1.99 .4 .49)$ & & \\
\hline
\end{tabular}

\section{Figure 3}

Effect size of TyG index on incident T2DM in each subgroup. Notes: adjust for age, sex, height, weight, LDL, TC, HDL-C, BUN, Ccr, AST, ALT, SBP, DBP, drinking status, smoking status and family history of diabetes. 